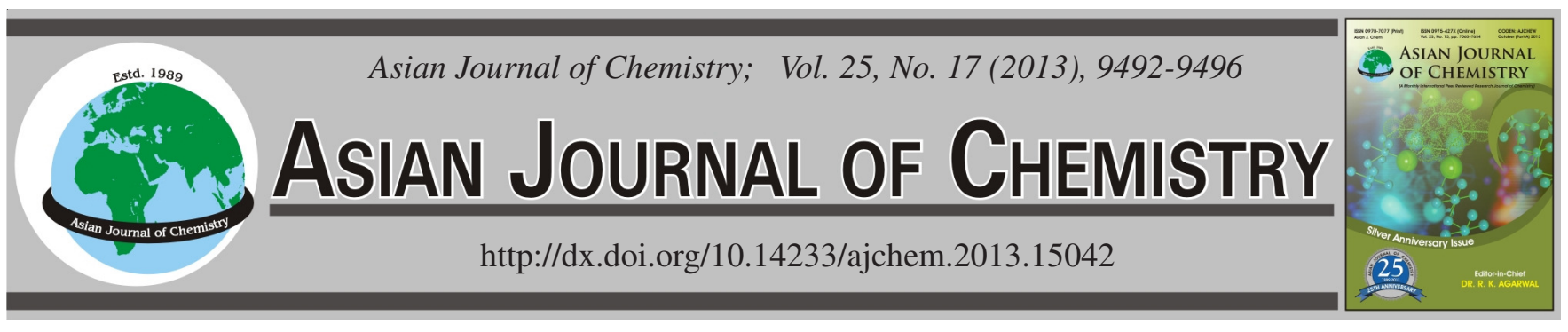

\title{
Kinetics and Thermodynamics Studies of Glycyrrhizic Acid Adsorption Using S-8 Macroporous Resin
}

\author{
Xiujuan He, Jianming Dan ${ }^{*}$ and Chenglin Hong
}

College of Chemistry and Chemical Engineering/Key Laboratory for Green Processing of Chemical Engineering of Xinjiang Bingtuan, Shihezi University, Shihezi 832003, Xinjiang Province, P.R. China

*Corresponding author: E-mail: djm_tea@shzu.edu.cn

(Received: 26 December 2012;

Accepted: 1 October 2013)

AJC-14212

\begin{abstract}
Simple method for adsorption of glycyrrhizic acid tri-ammonium salt from aqueous solution by the macroporous resin was presented in this work. Static adsorption studies were used for comparing the adsorption capacities of the nine resins, S-8, H1020, NKA, X-5, D4006, D101, AB-8, NKA-II and NKA-9, respectively. The results showed that S-8 resin had the best adsorption capacity. The maximum adsorption capacity of resin S-8 for glycyrrhizic acid tri-ammonium salt was found to be $75.06 \mathrm{mg} / \mathrm{g}$ at $303 \mathrm{~K}$. Exploring the static adsorption isotherms, kinetics and thermodynamics on macroporous adsorption resin S-8 from glycyrrhizic acid tri-ammonium salt aqueous solutions. The adsorption isotherm data could be well described by the Langmuir and from which the adsorption capacity was obtained. The adsorption kinetics well fitted using a pseudo second-order kinetic model. Thermodynamic parameters (i.e., change in the free energy $(\Delta \mathrm{G})$, the enthalpy $(\Delta \mathrm{H})$ and the entropy $(\Delta \mathrm{S}))$ were evaluated and indicate that the adsorption of glycyrrhizic acid triammonium salt onto the $\mathrm{S}-8$ resin was a spontaneous reaction and endothermic process.
\end{abstract}

Key Words: Glycyrrhizic acid, Adsorption, Macroporous resin, Kinetic, Isotherm.

\section{INTRODUCTION}

Licorice (Gancao in Chinese), the dried roots and rhizomes of Glycyrrhiza uralensis Fisch., Glycyrrhiza inflata Bat. Glycyrrhiza glabra L., has been widely used traditional medicinal herbs in Eastern and Western for over 2000 years ${ }^{1,2}$. Glycyrrhizic acid (GA. also referred to as glycyrrhizin), a glycosylated saponin with a pentacyclic triterpenic structure bound to two molecules of glucuronic acids as seen in Fig. 1(I), is the main active ingredient of licorice ${ }^{3}$.

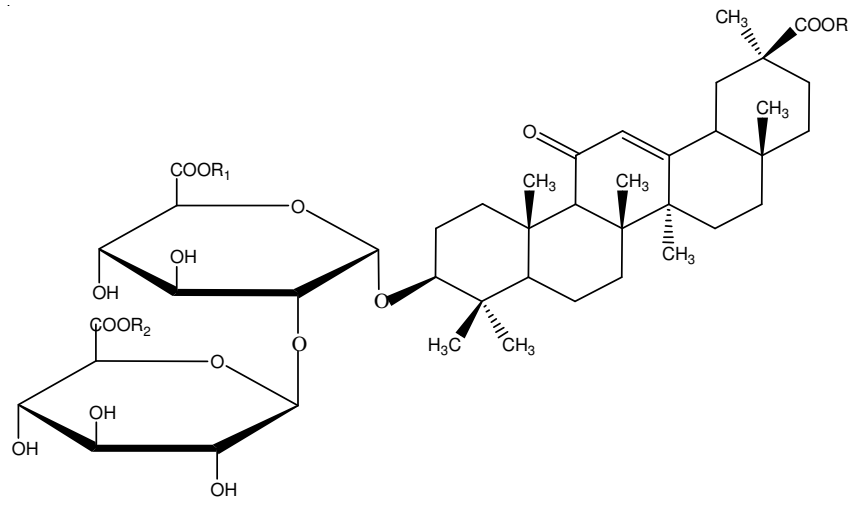

Fig. 1. Chemical structure of glycyrrhizic acid. (I): $R=R_{1}=R_{2}=H$, (II): $R$ $=\mathrm{R}_{1}=\mathrm{R}_{2}=\mathrm{NH}_{4}$
With modern medical research of licorice, glycyrrhizic acid and its salts shows a variety of pharmacological activities, including anti-ulcer, antiinflammatory, antioxidative, anticancer, antiallergic, antiviral, antidepressive, antidiabetic and memory enhancing activities ${ }^{4,5}$, especially the therapy of patients with AIDS and hepatitis B. Due to its high sweet taste and low calorific value, approximately 250 times sweeter than sucrose, glycyrrhizic acid is applied as a sweetener in food products, beverage and tobacco ${ }^{6}$. So, it is used extensively in the pharmaceutical industry, confectionary, food and tobacco in the whole world.

At present, the international market demands for glycyrrhizic acid largely, especially the higher purity of glycyrrhizic acid. For a long time, separation and purification of glycyrrhizic acid from extract of glycyrrhizic acid is a daunting task. Extract of glycyrrhizic acid in addition to containing glycyrrhizic acid also contains many impurities, such as reducing sugar, pectin, protein, starch and flavonoids and other substances?

Several kinds of technologies have been utilized for separation and purification glycyrrhizic acid from licorice extract, includes solvent extraction, adsorption, chromatography, ultrafiltration. The solvent extraction method for the separation and purification of glycyrrhizic acid is the most commonly used. However, the operation more steps, the process is complicated 
and a variety of organic solvents are mixed together brought to the recycling difficult. Tian et al $^{8}$ developed a method of simultaneous extraction and separation of liquiritin, glycyrrhizic acid and glabridin from licorice using liquid-liquid extraction with liquid chromatography separation. $1.43 \mathrm{mg} / \mathrm{g}$ for glycyrrhizic acid were obtained and the recoveries $89.7 \%$. This method had high cost and a small amount of the treated sample. Madaeni et al. ${ }^{9}$ used nanofiltration (NRT-7450) membrane separated liquiritin from glycyrrhizic acid in licorice aqueous solutions and obtained recoveries for glycy-rrhizic acid between $0.65-1.86 \%$. The ultrafiltration method had highenergy consumption and membrane pollution.

Macroporous adsorption resin is a kind of porous solid structure, artificial syntheses of organic polymer adsorbent. It has some advantages, including big adsorption capacity, simple procedure, low cost, easy regeneration and high-yield ${ }^{10}$. Macroporous adsorption resins have frequently used to recover pigments and other products from plant extracts ${ }^{11}$.

Geng et al. ${ }^{12}$ through the comparison of the adsorption and desorption rates of six types of macroporous resin adsorption used to purify the pigment from Hibiscus syriacus L. petals. Yang et al. ${ }^{13}$ studied the performance and separation characteristics of 21 types macroporous resins for the enrichment and purification of deoxyschizandrin and $\gamma$-schizandrin, the results, HPD500 was the best. Fu et al. ${ }^{14}$ compared the performance and adsorption characteristics from 4 types macroporous resins for separation of glycyrrhizic acid and licorice flavonoids (LF), XDA-1 offers much higher adsorption capacity for glycyrrhizic acid and licorice flavonoids than other resins and an enriched glycyrrhizic acid extracted with $66 \%$ purity can be separated from crude licorice extracted in one run.

The adsorption of a solute on macroporous resin is a complex process. Therefore, the development of reliable mathematical models that can accurately describe and predicate experimental data of adsorption would be extremely helpful in understanding the adsorption process as well as optimizing the design of adsorption systems.

The objective of this research is to investigate the adsorption kinetics and isotherm models of glycyrrhizic acid tri-ammonium salt adsorption by $\mathrm{S}-8$ resin at varying temperatures. Kinetic data can be used to predict the rate at which the glycyrrhizic acid tri-ammonium salt is adsorption from aqueous solution and equilibrium adsorption isotherms are used to quantify the adsorption capacity of an adsorbent (e.g., S-8). Furthermore, the thermodynamic process of glycyrrhizic acid tri-ammonium salt adsorption on S-8 resin was explored.

\section{EXPERIMENTAL}

UV-VIS spectrophotometer (Cintra20, GBC Instrument Co., Ltd., Astrulia), vacuum drying oven(DZF-1, Beijing guangming medical instrument plant, China), digital display Constant temperature water bath (HH-S, Jintan city medical instrument plant, China), low speed high volume tube centrifuge (LXJ-IIB, Shanghai anting scientific instruments plant, China), air bath oscillator (HZQ-C, Harbin east medical instrument plant, China).

Main reagents: Extractum glycyrrhizae was purchased from a local market. Standard sample of glycyrrhizic acid ammonium salt (Chendu Mansite Pharmacetical Co., Ltd., Chendu, China ) was obtained from Mansite. All other chemicals were purchased from Tianjin Fuyu Chemicals Co. (Tianjin, China), unless otherwise stated.

Macroporous resins, including H1020, NKA, X-5, D4006, D101, AB-8, NKA-II and NKA-9 (Nankai University, Tianjing, China). Macroporous resin of S-8 (Cangzhou Bon Adsorber Technology Co., Ltd., Cangzhou, China), All the used resin structure is crosslinked-polystyrene and the physical and chemical properties parameters in Table-1.

Preparation of crude extract: Dried extractum glycyrrhizae $100.00 \mathrm{~g}$ were extracted with distilled water $1000 \mathrm{~mL}$ at $80^{\circ} \mathrm{C}$ for $2 \mathrm{~h}$ and filtered. The water solution of extract was cooling to room temperature after centrifugal. Then, the centrifugal solid put into vacuum drying oven dryness, at last get glycyrrhizic acid of crude product.

It accurately weighed $30 \mathrm{~g}$ dried glycyrrhizic acid of crude product, used acetone as solid to the liquid ratio of 1:8, 1:6, $1: 5$, respectively, was reflux extracted three times for $1.5 \mathrm{~h}$, centrifuged and collecting supernatant fluid, after cooling to room temperature, add ammonia solution into the supernatant fluid, adjust supernatant fluid $\mathrm{pH}$ at 7-8, standing $3 \mathrm{~h}$ centrifuged. After the centrifugal solid put into dry get glycyrrhizic acid tri-ammonium salt (glycyrrhizic acid tri-ammonium salt) as seen in Fig. 1(II) product.

Calibration curve and glycyrrhizic acid tri-ammonium salt sample measurements: Accurately weight glycyrrhizic acid ammonium salt was transferred to the volumetric flask of $25 \mathrm{~mL}$, followed by $50 \%$ ethanol and saved at a low temperature after shaking evenly before use. Accurately measured glycyrrhizic acid ammonium salt solution of 1, 2, 3, 4, 5, 6 and $7 \mathrm{~mL}$ were transferred to the measuring flasks respectively. Absorbance values of standard solution at the wavelength $\lambda=254 \mathrm{~nm}$ were measured and drew the standard curve. From the standard

TABLE-1

PHYSICAL AND CHEMICAL PROPERTIES OF THE RESIN USED IN STUDY*

\begin{tabular}{ccccc}
\hline Resins & Polarity & Surface area $\left(\mathrm{m}^{2} / \mathrm{g}\right)$ & Average pore radius $(\AA)$ & Particle diameter $(\mathrm{mm})$ \\
\hline H1020 & Non-polar & $700-1000$ & $120-170$ & $0.300-1.25$ \\
NKA & Non-polar & $570-590$ & $200-220$ & $0.300-1.00$ \\
X-5 & Non-polar & $500-600$ & $290-300$ & $0.300-1.25$ \\
D4006 & Non-polar & $400-440$ & $65-75$ & $0.300-1.25$ \\
D101 & Non-polar & $480-520$ & $250-280$ & $0.300-1.25$ \\
AB-8 & Weak-polar & $480-520$ & $130-140$ & $0.300-1.25$ \\
NKA-II & Polar & $160-200$ & $145-155$ & $0.300-1.25$ \\
NKA-9 & Polar & $250-290$ & $155-165$ & $0.300-1.25$ \\
S-8 & Strong-polar & 100 & $250-300$ & $0.315-1.25$ \\
\hline
\end{tabular}


curve, $\mathrm{A}$ is the absorbance value at $254 \mathrm{~nm}$ and $\mathrm{c}$ is the concentration of glycyrrhizic acid ammonium salt and the regression equation was determined to be $\mathrm{A}=12.9881 \mathrm{c}-0.0426\left(\mathrm{R}^{2}\right.$ $=0.9998)$, linear range of 10.0-70.0 mg/L. The sample of glycyrrhizic acid tri-ammonium salt used the same steps and higher levels of glycyrrhizic acid tri-ammonium salt could be detected by appropriate dilution of the sample.

Pretreatment of macropous resin: The resins were soaked in $95 \%$ ethanol for $24 \mathrm{~h}$. After socking the resins were continuously cleaned with $95 \%$ ethanol. The eluate was added with distilled water until the solution was not muddy. With 5 $\% \mathrm{HCl}$ and $2 \% \mathrm{NaOH}$, respectively, soaked resins for $6.0 \mathrm{~h}$ and then washed with distilled water to a neutral. Pretreatment of the resins was stored in distilled water.

Static adsorption capacity and desorption ratio: The procedures of adsorption experiments were performed as follows: Suitable amount of nine resins (each resin weight 2.00 g) was mixed in a $150 \mathrm{~mL}$ conical flask with concentration $1.79 \mathrm{mg} / \mathrm{mL} 90.0 \mathrm{ml}$ of glycyrrhizic acid tri-ammonium salt sample solution. The conical flasks were continuously stirred in air bath oscillator at frequency $100 \mathrm{rpm}$ kept temperature at $303 \mathrm{~K}$ for $24 \mathrm{~h}$ to establish the adsorption equilibrium. The supernatant solution was sampled, filtrated and measured by UV-VIS. The adsorption capacity of resin and adsorption ratio were calculated with the formula:

$$
\begin{gathered}
\mathrm{Q}_{\mathrm{e}}=\frac{\left(\mathrm{C}_{0}-\mathrm{C}_{\mathrm{e}}\right) \mathrm{V}}{\mathrm{m}} \\
\mathrm{E}_{0}=\frac{\mathrm{C}_{0}-\mathrm{E}_{\mathrm{e}}}{\mathrm{C}_{0}} \times 100 \%
\end{gathered}
$$

where $\mathrm{Q}_{\mathrm{e}}$ is equilibrium adsorption capacity of glycyrrhizic acid tri-ammonium salt in the resin $(\mathrm{mg} / \mathrm{g}), \mathrm{C}_{0}$ is initial concentration of glycyrrhizic acid tri-ammonium salt $(\mathrm{mg} / \mathrm{mL}), \mathrm{C}_{\mathrm{e}}$ is equilibrium concentration of glycyrrhizic acid tri-ammonium salt $(\mathrm{mg} / \mathrm{mL}), \mathrm{V}$ is added volume of the sample solution $(\mathrm{mL})$ and $\mathrm{m}$ is mass of resin $(\mathrm{g}), \mathrm{E}_{0}$ is the adsorption ratio.

After adsorption equilibrium was reached, the supernatant solution was discarded by filtration and the adsorption saturated resin was washed $10 \mathrm{~mL}$ with distilled water. It added $70 \mathrm{~mL}$ $70 \%$ ethanol solutions and the adsorption saturated resin in the conical flask was continuously stirred at $100 \mathrm{rpm} 303 \mathrm{~K}$ for $24 \mathrm{~h}$ to establish a desorption ratio of glycyrrhizic acid triammonium salt from the resin. The supernatant solution was sampled, filtrated and measured by UV-VIS. Desorption ratio of glycyrrhizic acid tri-ammonium salt was calculated with the follow formula:

$$
\mathrm{D}=\frac{\mathrm{C}_{\mathrm{a}} \times \mathrm{V}_{1}}{\left(\mathrm{C}_{0}-\mathrm{C}_{\mathrm{e}}\right) \times \mathrm{V}_{2}} \times 100 \%
$$

where $\mathrm{D}$ is the desorption ratio, $\mathrm{C}_{\mathrm{a}}$ is the concentration of glycyrrhizic acid tri-ammonium salt in the desorption solution $(\mathrm{mg} / \mathrm{mL}), \mathrm{V}_{1}$ is added volume of desorption solvent $(70 \mathrm{~mL}$ $70 \%$ ethanol), $\mathrm{V}_{2}$ is added volume of adsorption equilibrium solution $(\mathrm{mL})$.

Adsorption kinetics: The adsorption kinetics of the macoroporous resin was studied pretreatment $\mathrm{S}-8$ type resin two copies (each resin weight $1.00 \mathrm{~g}$ ) and separately added $100 \mathrm{~mL}$ concentration of glycyrrhizic acid tri-ammonium salt
$0.21 \mathrm{mg} / \mathrm{mL}, 0.41 \mathrm{mg} / \mathrm{mL}$ in a conical flask. And the conical flasks were continuously stirred at $100 \mathrm{rpm}$ at $303 \mathrm{~K}$ for $9 \mathrm{~h}$. Similarly, the concentration of glycyrrhizic acid tri-ammonium salt in the supernatant was measured by UV-VIS at a designated time-point $0,30,60,90,150,210,270,390$ and $510 \mathrm{~min}$, respectively.

The adsorption kinetics is important as it controls the process efficiency. For evaluating the adsorption kinetics of glycyrrhizic acid tri-ammonium salt different kinetic models have been used to test experimental data.

The line form of pseudo-first order rate equation for use in the kinetic analysis of data is

$$
\ln (1-\mathrm{F})=-\mathrm{k}_{1} \mathrm{t}
$$

where $\mathrm{F}=\mathrm{Q}_{\mathrm{t}} / \mathrm{Q}_{\mathrm{e}}$ is adsorption fraction at $\mathrm{t}$ moment, $\mathrm{Q}_{\mathrm{e}}$ is equilibrium adsorption capacity of glycyrrhizic acid tri-ammonium salt in the resin $(\mathrm{mg} / \mathrm{g}), \mathrm{Q}_{\mathrm{t}}$ is adsorption capacity of glycyrrhizic acid tri-ammonium salt in the resin at designated time-point $t$ $(\mathrm{mg} / \mathrm{g}), \mathrm{k}_{1}$ is pseudo-first order rate constant $\left(\mathrm{min}^{-1}\right)$. A straight line was obtained by plotting $\ln (1-\mathrm{F})$ versus $\mathrm{t}$.

The pseudo-second order rate kinetic model is linearly expressed as:

$$
\frac{\mathrm{t}}{\mathrm{Q}_{\mathrm{t}}}=\frac{1}{\mathrm{k}_{2} \mathrm{Q}_{\mathrm{e}}^{2}}+\frac{1}{\mathrm{Q}_{\mathrm{e}}} \mathrm{t}
$$

where $\mathrm{k}_{2}$ is pseudo-second order rate constant $[\mathrm{g} /(\mathrm{mg} \mathrm{h})]$, which can be calculated from the intercept of the straight line obtained by plotting $t / Q_{t}$ versus $t$.

The Kannan equation of intra-particle diffusion was as following:

$$
\mathrm{Q}_{\mathrm{t}}=\mathrm{k}_{\mathrm{i}} \mathrm{t}^{1 / 2}+\mathrm{C}
$$

where $k_{i}$ is intra-particle diffusion constant $\left(\mathrm{g} /\left[\mathrm{mg} \mathrm{h}^{1 / 2}\right]\right), \mathrm{C}$ is constant.

Adsorption isotherms and thermodynamics: The adsorption isotherms were obtained under the following conditions: at each temperatures 293, 303 and $313 \mathrm{~K}, 2.00 \mathrm{~g} \mathrm{~S}-8$ resin was separately added into the $60 \mathrm{~mL}$ glycyrrhizic acid triammonium salt solution for adsorption, whose initial concentration of the glycyrrhizic acid tri-ammonium salt solution was $1.17,2.00,2.72,3.42$ and $4.16 \mathrm{mg} / \mathrm{mL}$, respectively. Langmuir and Freundlich models were used to evaluate the test data and to interpret the possible adsorption mechanism.

The Freundlich isotherm model assumes a heterogeneous and patch-wise surface that is independent of one another. The predigestion equation is as follows:

$$
\ln \mathrm{Q}_{\mathrm{e}}=\ln \mathrm{K}_{\mathrm{f}}+\frac{1}{\mathrm{n}} \ln \mathrm{C}_{\mathrm{e}}
$$

where $\mathrm{Q}_{\mathrm{e}}$ is equilibrium adsorption capacity of glycyrrhizic acid tri-ammonium salt in the resin $(\mathrm{g} / \mathrm{g}), \mathrm{K}_{\mathrm{f}}$ and $\mathrm{n}$ are both the Freundlich constants. $\mathrm{K}_{\mathrm{f}}$ reflects the adsorption capacity of the adsorbent and $\mathrm{n}$ reflects the adsorption affinity of the adsorbent to the adsorbate, $\mathrm{C}_{\mathrm{e}}$ is adsorption equilibrium concentration of glycyrrhizic acid tri-ammonium salt in solution $(\mathrm{g} / \mathrm{L})$.

The Langmuir isotherm model assumes that homogeneous monolayer surface adsorption occurs and can be written as:

$$
\frac{\mathrm{C}_{\mathrm{e}}}{\mathrm{Q}_{\mathrm{e}}}=\frac{\mathrm{C}_{\mathrm{e}}}{\mathrm{Q}_{\mathrm{m}}}+\frac{1}{\mathrm{~K}_{\mathrm{I}} \mathrm{Q}_{\mathrm{m}}}
$$


where $\mathrm{Q}_{\mathrm{m}}$ is maximum adsorption capacity of the adsorbent $(\mathrm{mg} / \mathrm{g}), \mathrm{K}_{\mathrm{I}}$ is Langmuir constant.

The thermodynamic parameters change of Gibbs free energy $(\Delta \mathrm{G})$, change of enthalpy $(\Delta \mathrm{H})$ and change in entropy $(\Delta \mathrm{S})$ for present process were calculated using following equations:

$$
\begin{gathered}
\ln \mathrm{C}_{\mathrm{e}}=\frac{\Delta \mathrm{H}}{\mathrm{RT}}-\ln \left(\mathrm{K}_{0}\right) \\
\Delta \mathrm{G}=-\mathrm{nRT} \\
\Delta \mathrm{S}=\frac{(\Delta \mathrm{H}-\Delta \mathrm{G})}{\mathrm{T}}
\end{gathered}
$$

where $\mathrm{C}_{\mathrm{e}}$ is equilibrium concentration of glycyrrhizic acid triammonium salt in solution $(\mathrm{mg} / \mathrm{mL}), \Delta \mathrm{H}$ is change of enthalpy, $\mathrm{R}$ is ideal gas constant $[8.314 \mathrm{~J} /(\mathrm{mol} \mathrm{K})]$, $\mathrm{T}$ is absolute temperature $(\mathrm{K}), \mathrm{K}_{0}$ is a thermodynamic constant, $\Delta \mathrm{G}$ is change of Gibbs free energy, $\mathrm{n}$ is coefficient of the Freundlich isothermal equation, $\Delta \mathrm{S}$ is change of entropy.

\section{RESULTS AND DISCUSSION}

Static adsorption capacity and desorption ratio: H1020, NKA, X-5, D4006, D101, AB-8, NKA-II, NKA-9 and S-8 types of macroporous adsorption resins were used to separate and purify glycyrrhizic acid tri-ammonium salt. The adsorption capacity, the desorption rates were compared. Adsorption capacity, adsorption rate and desorption rate data obtained by eqns. 1-3 are given in Table- 2 .

\begin{tabular}{cccc}
\multicolumn{4}{c}{ TABLE-2 } \\
\multicolumn{4}{c}{$\begin{array}{c}\text { ADSORPTION AND DESORPTION EFFECTS } \\
\text { OF THE MACROPOROUS RESINS }\end{array}$} \\
\hline \multirow{2}{*}{ Resins } & $\begin{array}{c}\text { Adsorption } \\
\text { capacity (mg/g) }\end{array}$ & $\begin{array}{c}\text { Adsorption rate } \\
(\%)\end{array}$ & $\begin{array}{c}\text { Desorption rate } \\
(\%)\end{array}$ \\
\hline H1020 & 48.14 & 59.83 & 89.27 \\
NKA & 54.90 & 68.23 & 92.94 \\
X-5 & 54.72 & 68.01 & 92.27 \\
D4006 & 43.64 & 54.23 & 90.36 \\
D101 & 56.45 & 70.17 & 90.00 \\
AB-8 & 53.68 & 66.72 & 94.00 \\
NKA-II & 47.27 & 58.76 & 76.70 \\
NKA-9 & 37.05 & 46.05 & 91.77 \\
S-8 & 75.06 & 93.3 & 10.61 \\
\hline
\end{tabular}

The differences in the adsorption capacities were due to the surface areas and polarities of the resins. As can be seen in Table-2, S- 8 resin had the highest adsorption capacity and the lowest desorption rate. These results indicated that the S-8 resin adsorption glycyrrhizic acid tri-ammonium salt was strong, with $70 \%$ ethanol as the desorption solution was difficult to glycyrrhizic acid tri-ammonium salt eluted from S-8 resin. The desorption rate significant increase when we selected ethanol and acetone mixture as the desorption solution.
Adsorption kinetics: The adsorption kinetics curves for glycyrrhizic acid tri-ammonium salt on S-8 resin were obtained. As can be seen from Fig. 2, the adsorption capacity of glycyrrhizic acid tri-ammonium salt increased with the adsorption time, reaching equilibrium at about $210 \mathrm{~min}$. During the first $210 \mathrm{~min}$, the adsorption capacities increased rapidly and after $210 \mathrm{~min}$ the slopes reached equilibrium.

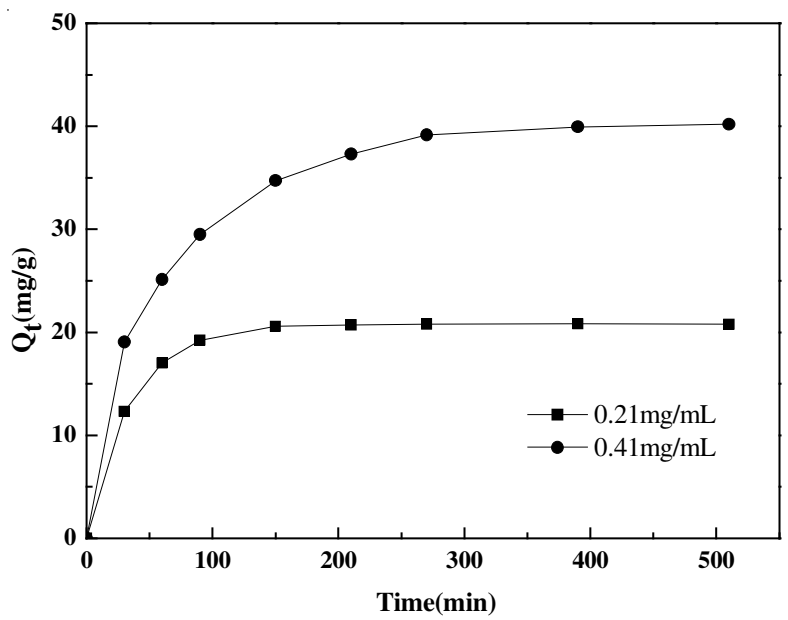

Fig. 2. Static adsorption kinetics of glycyrrhizic acid tri-ammonium salt on the resin S-8

The equations of pseudo-first-order, pseudo-secondorder and particle diffusion kinetics models and dynamic parameters are shown in Table-3. In terms of the calculated linear regression correlation coefficients of kinetics models for S-8 resin, the pseudo-second-order kinetics model was considered to be the most favorable model for illustration of the whole adsorption processes of glycyrrhizic acid triammonium salt on $\mathrm{S}-8$ resin.

Adsorption isotherms and thermodynamics: Freundlich and Langmuir model to describe the adsorption phenomena. The corresponding equations are listed in Tables 4 and 5.

\begin{tabular}{ccccc}
\multicolumn{7}{c}{ TABLE-4 } \\
\multicolumn{4}{c}{ ISOTHERMS EQUATIONS AND PARAMETERS OF } \\
\multicolumn{4}{c}{ FREUNDLICH ADSORPTION ISOTHERMS ON S-8 RESIN } \\
\hline Temp. $(\mathrm{K})$ & Isotherms equation & $\mathrm{K}_{\mathrm{f}}$ & $\mathrm{n}$ & $\mathrm{R}^{2}$ \\
\hline 293 & $\operatorname{lnQ}_{\mathrm{e}}=0.4002 \operatorname{lnC}_{\mathrm{e}}-1.520$ & 0.2187 & 2.499 & 0.7323 \\
303 & $\operatorname{lnQ}_{\mathrm{e}}=0.4019 \operatorname{lnC}_{\mathrm{e}}-1.496$ & 0.2240 & 2.488 & 0.7330 \\
313 & $\operatorname{lnQ}_{\mathrm{e}}=0.3755 \operatorname{lnC}_{\mathrm{e}}-1.572$ & 0.2076 & 2.663 & 0.7170 \\
\hline
\end{tabular}

\begin{tabular}{ccccc}
\multicolumn{7}{c}{ TABLE-5 } \\
ISOTHERMS EQUATIONS AND PARAMETERS OF \\
LANGMUIR ADSORPTION ISOTHERMS ON S-8 RESIN \\
\hline Temp. $(\mathrm{K})$ & Isotherms equation & $\mathrm{K}_{1}$ & $\mathrm{Q}_{\mathrm{m}}$ & $\mathrm{R}^{2}$ \\
\hline 293 & $\mathrm{C}_{\mathrm{e}} / \mathrm{Q}_{\mathrm{e}}=7.554 \mathrm{C}_{\mathrm{e}}+0.3072$ & 24.59 & 0.1324 & 0.9842 \\
303 & $\mathrm{C}_{\mathrm{e}} / \mathrm{Q}_{\mathrm{e}}=7.388 \mathrm{C}_{\mathrm{e}}+0.3134$ & 23.57 & 0.1354 & 0.9825 \\
313 & $\mathrm{C}_{\mathrm{e}} / \mathrm{Q}_{\mathrm{e}}=7.527 \mathrm{C}_{\mathrm{e}}+0.3033$ & 24.82 & 0.1329 & 0.9852 \\
\hline
\end{tabular}

\begin{tabular}{|c|c|c|c|c|c|c|c|c|}
\hline \multirow{2}{*}{$\begin{array}{c}\text { Concentration } \\
(\mathrm{mg} / \mathrm{mL})\end{array}$} & \multicolumn{2}{|c|}{ Pseudo-first-order } & \multicolumn{3}{|c|}{ Pseudo-second-order } & \multicolumn{3}{|c|}{ Intra-particle diffusion } \\
\hline & $\mathrm{k}_{1}(/ \min )$ & $\mathrm{R}_{1}{ }^{2}$ & $\mathrm{k}_{2}[\mathrm{mg} /(\mathrm{g} \mathrm{h})]$ & $\mathrm{Q}_{\mathrm{e}}(\mathrm{mg} / \mathrm{g})$ & $\mathrm{R}_{2}^{2}$ & $\mathrm{k}_{\mathrm{i}}\left[\mathrm{mg} /\left(\mathrm{g} \mathrm{h}^{1 / 2}\right)\right]$ & $\mathrm{C}(\mathrm{mg} / \mathrm{g})$ & $\mathrm{R}_{3}{ }^{2}$ \\
\hline 0.21 & 0.0235 & 0.9858 & 0.0291 & 21.55 & 0.9990 & 3.041 & 13.73 & 0.7947 \\
\hline 0.41 & 0.0123 & 0.9965 & 0.0342 & 43.86 & 0.9993 & 4.441 & 16.64 & 0.8550 \\
\hline
\end{tabular}

TABLE-3

KINETIC PARAMETERS FOR ADSORPTION OF GLYCYRRHIZIC ACID TRI-AMMONIUM SALT ON S-8 RESIN 
TABLE-6

THERMODYNAMIC PARAMETERS OF ADSORPTION*

\begin{tabular}{cccccccc}
\hline \multirow{2}{*}{ Qs $(\mathrm{mg} / \mathrm{g})$} & \multirow{2}{*}{$\Delta \mathrm{H}(\mathrm{kJ} / \mathrm{mol})$} & \multicolumn{3}{c}{$\Delta \mathrm{G}(\mathrm{kJ} / \mathrm{mol})$} & \multicolumn{4}{c}{$\Delta \mathrm{S}(\mathrm{kJ} / \mathrm{mol} \mathrm{K})$} \\
\cline { 3 - 8 } & & $293 \mathrm{~K}$ & $303 \mathrm{~K}$ & $313 \mathrm{~K}$ & $293 \mathrm{~K}$ & $303 \mathrm{~K}$ & $313 \mathrm{~K}$ \\
\hline 40 & -37.392 & & & -0.107 & -0.103 & -0.097 \\
80 & -41.680 & \multirow{2}{*}{-6.088} & -6.268 & -6.930 & -0.122 & -0.117 & -0.111 \\
120 & -44.188 & & & -0.130 & -0.125 & -0.119 \\
160 & -45.968 & & & -0.136 & -0.131 & -0.125 \\
\hline
\end{tabular}

$* \mathrm{Qs}$, adsorption capacity of resin; $\Delta \mathrm{H}$, change of enthalpy; $\Delta \mathrm{G}$, change of Gibbs free energy; $\Delta \mathrm{S}$, change of entropy.

The adsorption isotherms for glycyrrhizic acid tri-ammonium salt onto S-8, were fitted with the Langmuir and Freundlich equation, respectively. Herein, the parameters corresponding to the Freundlich and Langmuir regression equations for other experimental conditions are shown in Table- 4 .

Tables 4 and 5 showed that the Langmuir model fitted the experimental data better than Freundlich model. The fitted line by Langmuir model with a high squared correlation coefficient may originate from the formation of a thin film on the surface of the S-8 resin. However, the Langmuir equation is based on the assumption on a homogeneous adsorbent surface, while on the surface of macroporous S-8 resin, there are so much voids which are inhomogeneous.

The value $n>1$ represents the favorable adsorption condition. In most cases, the exponent $1<\mathrm{n}<10$ shows beneficial adsorption $^{15}$. As shown in Table-4, $\mathrm{n}$ value was more than 1 , which demonstrated that the adsorption of S-8 resin to glycyrrhizic acid tri-ammonium salt was optimal adsorption, that was, the adsorption was easy to proceed.

The thermodynamic parameters for the $\mathrm{S}-8$ resin at different temperatures are listed in Table- 6 .

As can be seen in Table-6, the changes in enthalpy values were negative for S-8 resin, indicating that the adsorption of glycyrrhizic acid tri-ammonium salt on the resin was an exothermic process in nature. In this study, the absolute values of $\Delta \mathrm{H}$ were less than $46 \mathrm{~kJ} / \mathrm{mol}$ for $\mathrm{S}-8$ resin, which suggested that the adsorption of glycyrrhizic acid tri-ammonium salt on the resin was controlled by physical rather than chemical mechanism. The changes in Gibbs free energy $(\Delta G)$ is the energy required for the adsorption of unit adsorbate on the resin at a given temperature. The values of $\Delta \mathrm{G}$ were negative at all the temperatures and for the $\mathrm{S}-8$ resin studied, which indicated that the adsorption was a spontaneous process. The absolute values of $\Delta \mathrm{G}$ were lower than $20 \mathrm{~kJ} / \mathrm{mol}$, which indicated the physisorption nature of present adsorption process. The change of entropy $(\Delta S)$ is negative, demonstrating that the adsorption process is an entropy reducing process.

\section{Conclusion}

The present study reported experimental data on the separation and purification of glycyrrhizic acid tri-ammonium salt at various operating parameters in terms of S-8 macroporous resin. The maximum adsorption capacity of resin S-8 for glycyrrhizic acid tri-ammonium salt was found to be 75.06 $\mathrm{mg} / \mathrm{g}$ at $303 \mathrm{~K}$. The Freundlich and Langmuir models were employed to fit experimental data. The results of regression showed that the Langmuir equation is more suitable.

Some thermodynamic parameters were calculated. The changes in enthalpy for adsorbent was negative and the absolute value was lower than $46 \mathrm{KJ} / \mathrm{mol}$, which indicated that the adsorption process was exothermic and mainly physical. The changes in Gibbs free energy for adsorbent was negative too, which indicated that the adsorption occurred spontaneously.

\section{REFERENCES}

1. Pharmacopeia of People's Republic of China: Chinese Pharmacopeia Commission, Chemical Industry Press (2005).

2. C. Sabbioni, A. Ferranti, F. Bugamelli, G.C. Forti and A.A. Raggi, Phytochem. Anal., 17, 25 (2006).

3. J.R. Hennell, S. Lee, C.S. Khoo, M.J. Gray and A. Bensoussan, J. Pharm. Biomed. Anal., 47, 494 (2008).

4. R.A. Isbrucker and G.A Burdock, Regul. Toxicol. Pharm., 46, 167 (2006).

5. Q.-Y. Zhang and M. Ye, J. Chromatogr. A, 1216, 1954 (2009).

6. B. Ploeger, T. Mensinga, A. Sips, J. Meulenbelt and J. DeJongh, Pharm. Res., 17, 1516 (2000).

7. Lu Shou-Ping, Sun Qun, Wang Jian-Hua et al., China J. Chin. Mater. Med., 31, 357 (2006).

8. M.-L. Tian, H,-Y. Yan and K.H. Row, Biotechnol. Bioproeess Eng., 13, 671 (2008)

9. S.S. Madaeni, M.R. Sohrabi, M. Khosravi and A.M. Ghaedi, Sep. Sci. Technol., 46, 1406 (2011).

10. R.J. Ju, R.J. Huang, J. Zhou, R.J. Li, P. Zhou, Z.H. Zhang, F.J. Xiang, D.J. Xu, W.X. Liu, X.T. Ma, Q. Zhang and W.L. Lu, Sci. China Chem., 55, 1435 (2012).

11. D. Kammerer, J.G. Kljusuric, R. Carle and A. Schieber, Eur. Food Res.Technol., 220, 431 (2005).

12. M.-J. Geng, M.-X. Ren, Z.-L. Liu and X.J. Shang, Afr. J. Biotechnol., 11, 429 (2012).

13. F.-J. Yang, C.-H. Ma, L. Yang, C.J. Zhao, Y. Zhang and Y.G. Zu, Molecules, 17, 3510 (2012).

14. B.Q. Fu, J. Liu, H. Li, L. Li, F.S.C. Lee and X.R. Wang, J. Chromatogr. A, 1089, 18 (2005).

15. C.-H. Xiong and C.-P. Yao, J. Hazard. Mater., 166, 815 (2009). 